\title{
Correction to: Timber Plate Shell Structures: A Digital Resurgence of Traditional Joining Methods
}

\author{
Christopher Robeller
}

\section{Correction to:}

Chapter "Timber Plate Shell Structures: A Digital

Resurgence of Traditional Joining Methods" in: Bianconi and M. Filippucci (eds.),

Digital Wood Design, Lecture Notes in Civil Engineering 24, https://doi.org/10.1007/978-3-030-03676-8_45

In the original version of the chapter, the author provided belated corrections have been incorporated. The chapter and the book now have been updated with changes. 